\title{
Os saberes profissionais dos professores
}

\author{
Maria Aparecida Vilela Mendonça Pinto Coelho*
}

\begin{abstract}
Resumo
O foco deste estudo é a aprendizagem profissional de um grupo de professoras e seus objetivos são: compreender como professoras de Matemática que pertencem a um grupo do tipo colaborativo problematizaram suas concepções sobre Educação Estatística e como o movimento do grupo possibilitou a sistematização de saberes profissionais das professoras. A questão investigativa é: Como o movimento do grupo mobilizou práticas de ensinar e aprender Estatística e possibilitou a sistematização de saberes profissionais das professoras? A pesquisa é qualitativa, buscando uma abordagem histórico-dialética. Ela apontou a necessidade de uma reformulação no currículo da Estatística na Escola Básica, na qual seja privilegiada a Literacia Estatística, ou seja, a interpretação e a compreensão dos resultados estatísticos. Alguns saberes das professoras foram sistematizados pelas interações dialógicas do grupo, pela contribuição do outro na produção do conhecimento e pelo debate e a contradição como instigadores da produção de sentidos.

Palavras-chave: Desenvolvimento profissional de professores; Educação matemática; Educação estatística; Grupo colaborativo; Saberes profissionais dos professores.
\end{abstract}

\section{Teachers' professional knowledge}

\begin{abstract}
This paper's central focus is the professional learning of a group of teachers and their goals are: to understand how Math teachers who are members of a collaborative group changed their concepts of Statistics Education as well as understanding how the group movement generated the systematization of teachers's professional knowledge. The investigative question was formulated as: How did the group movement enable the Statistics teaching and learning practices and resulted in the systematization of the teachers professional knowledge? The research is qualitative, seeking a historical-dialectical approach. She pointed out the need for an overhaul in Primary School Statistics curriculum, which is privileged Statistical Literacy, by the understanding and interpretation of statistical results. Some of the teachers'professional knowledge were systematized by groups dialogic interactions, the contribution of the other in knowledge production and by the debate and the contradiction as instigators to the production of meaning.

Keywords: Teachers'Professional Development; Mathematical Education; Statistical Education; Collaborative Group; Teachers'Professional Knowledge
\end{abstract}

\section{Introdução}

A pesquisa desenvolvida neste trabalho deu origem a uma tese de doutorado defendida recentemente e trata-se de uma investigação que tem seu foco na aprendizagem profissional de um grupo de professoras que se reunem com o objetivo de buscar parceiros para encontrar soluções para problemas de suas práticas pedagógicas e enfrentar os desafios da vida profissional. Este grupo de professoras vivenciou, profissionalmente, um período em que as mudanças nas práticas pedagógicas se mostravam imperativas, devido aos efeitos da globalização.

Todo o trabalho foi orientado pela concepção bakhtiniana de conhecimento, como verdade provisória e produzida nas relações interpessoais e dialógicas; pela constituição do outro na produção do conhecimento, sempre aberto a mudanças; e pelo debate e pela contradição como instigadores da produção de sentidos.

Nossa opção em investigar um grupo que aprende junto e produz conhecimento e sentidos na interação e em comunidades de aprendizagem profissionais está relacionada à nossa vivência como professora e pesquisadora, comprometida com a formação dos nossos alunos para um mundo fora da escola e com o futuro novo que se abre diante de nossos olhos, no qual perdem forças as iniciativas isoladas.

A realidade escolar mudou, ou deve mudar, para acompanhar as exigências do mundo globalizado e a escola tradicional, transmissiva, autoritária, não consegue exercer suas funções e deve ser modificada. Os saberes transmitidos pela escola não parecem mais corresponder aos saberes considerados socialmente úteis no mercado de trabalho e, a partir desse cenário, podemos

* Endereço eletrônico: cidapcoelho@ me.com 
vislumbrar um futuro que necessitará de novas relações entre saberes e práticas pedagógicas, e um novo modelo de profissionalidade docente.

O momento histórico vivido, em que os professores da rede pública estão sendo pressionados para apresentar resultados rápidos de melhora no desempenho dos alunos, sem que o contexto escolar e social tenha sido alterado, tem levado os professores a pensar em alternativas para fazer frente ao problema. Acreditamos que, embora a profissão docente esteja sofrendo uma crise de identidade, esta poderá ser produtiva, no sentido de mobilizar pesquisas e estudos que possam definir novos rumos para a solução do problema.

O modelo democrático, pautado no trabalho coletivo e contando com a participação efetiva dos sujeitos envolvidos, ainda não conseguiu impor-se. A reestruturação do trabalho docente exige uma nova escola e novas condições de trabalho, que possam fazer frente aos processos observados de precarização.

Neste trabalho faremos referência aos saberes profissionais dos professores como aquele saber fazer que é produzido nas práticas pedagógicas, aquela forma de cada professor trabalhar com seus alunos. A nossa concepção de saber profissional dos professores diz respeito aos saberes que cada professor desenvolve para cada turma, que só ele conhece, por vivenciar a sala de aula em seus aspectos particulares dentro de cada contexto.

\section{Aspectos metodológicos da investigação}

A pesquisa desenvolvida neste trabalho é de natureza qualitativa, buscando uma abordagem histórico-dialética, em uma vertente interpretativa, procurando apreender o caráter dinâmico, contraditório e histórico dos fenômenos educativos. A investigação orientou-se segundo duas vertentes: a Educação Estatística e o desenvolvimento profissional de professores.

A Educação Estatística foi escolhida como conteúdo básico da pesquisa devido aos nossos estudos sobre ela no grupo de pesquisa da universidade e às suas características epistemológicas que favorecem a problematização e o debate.

Nossos objetivos ficaram assim definidos:

- Compreender como professoras de Matemática do Ensino Básico que pertencem a um grupo do tipo colaborativo problematizaram suas concepções sobre Educação Estatística.

- Compreender como o movimento do grupo possibilitou a sistematização de saberes profissionais das professoras.

E nossa questão investigativa é: Como o movimento do grupo mobilizou as práticas de ensinar e aprender Estatística e possibilitou a sistematização de saberes profissionais das professoras?

Partimos da hipótese de que, ao colocar-se em um grupo, com o objetivo de problematizar suas práticas pedagógicas, o professor produz saberes e desenvolve-se profissionalmente. A possibilidade de tal produção baseia-se no pressuposto de que o conhecimento que os professores precisam para ensinar é gerado quando eles consideram suas próprias salas de aula como locais de uma investigação intencional.

Para atingirmos esses objetivos, contamos com a colaboração de um grupo formado por professoras interessadas em problematizar sua prática pedagógica, visando implementar mudanças avaliadas por elas como necessárias em sala de aula. Essas mudanças referem-se, principalmente, à atitude dos alunos em relação ao conhecimento matemático e estatístico, à autonomia e à argumentação.

Os debates no grupo e as narrativas das aulas foram os instrumentos usados na análise. Utilizamos como material as transcrições das reuniões do grupo ( de 24/08/2007 a 14/11/2008), o diário de campo das participantes, os vídeos das aulas de Estatística e os nossos memoriais (o registro escrito de nossas relações com o conhecimento matemático). Esse material foi também usado na produção dos textos que foram apresentados em congressos da área e no livro que publicamos.

No itens seguintes destacaremos alguns episódios das reuniões que podem servir de exemplo de como as professoras problematizaram suas práticas pedagógicas no grupo, algumas vezes instigadas pelo estudo dos textos teóricos, outras pela análise conjunta das aulas através do material vídeo-gravado e outras pela escrita conjunta do livro sobre a experiência ou pela preparação dos trabalhos que foram apresentados nos congressos da área.

\section{Os saberes profissionais dos professores}


Segundo Tadif (2002), a prática docente é uma atividade que mobiliza diversos saberes, como os pedagógicos, que se referem às concepções adquiridas durante a vida e que formam como um "arcabouço ideológico" à profíssão (TARDIF, 2002, p. 37), algumas formas de saber fazer e algumas técnicas. $\mathrm{O}$ autor cita também os saberes disciplinares (referentes à disciplina que ensinam), os saberes curriculares (dos objetivos, conteúdos, métodos de ensino) e, finalmente, os saberes experienciais, baseados em seu trabalho cotidiano e no conhecimento do seu meio. Destaca também que essas múltiplas articulações entre a prática docente e os saberes fazem dos professores um grupo social e profissional que tem necessidade de mobilizar esses diferentes saberes em sua prática

O episódio seguinte é revelador da nossa tentativa de produzir conhecimento estatístico de forma colaborativa. A professora Tânia continua a leitura do texto "Literacia estatística e o INAF 2002”, de Celi Aparecida Espasandin Lopes (2004).

TÂNIA $^{1}$ - A Estatística não se restringe à utilização de fórmulas e à realização de cálculos matemáticos. Ela requer certa sensibilidade da pessoa ao se aproximar dos dados, dados que envolvem incerteza e variabilidade, mesmo durante a coleta, permitindo, assim, que se possa tomar decisões em situação de incertezas.

PESQUISADORA - Isso foi o que vimos também no texto do Besson.

TÂNIA - Muitas vezes, acho que já fiz isso, restringia não a utilização de fórmulas, mas a construção de tabelas, porque quando você constrói essas tabelas você só faz cálculo. Mesmo eu pegando os cálculos deles, ficou muito sem questionamento.

PESQUISADORA - Eu também já fiz muito isso.

TÂNIA - Nós fomos educados assim. Muitas vezes pegando dados deles, eu não questionava, e a Estatística é isso, é você questionar o que a tabela está te oferecendo. Olha quanta coisa nova para mim, nós fomos criados com uma Matemática exata, não era Matemática de possibilidades, não é? Na minha faculdade não tive Estatística, eu lembro que a professora deu muita probabilidade. Mas, a Estatística eu vim conhecer dando aula, entendeu? E agora eu estou conhecendo o pensamento estatístico. É um processo
(06/06/2008).

A professora Tânia continua a refletir sobre o texto e, através dele, sobre sua prática pedagógica. Podemos perceber o seu conceito de Estatística em transformação, uma mudança em relação ao que ela revelou em episódios anteriores. Ela se refere à prática relatada pelos professores e muito incentivada pelos livros didáticos, que é a construção e a leitura de informações explícitas em gráficos. A professora Tânia parece perceber, nesse trabalho, também uma abordagem técnica, sem questionamento. Ela continua sua reflexão, destacando que o fato de trabalhar em sala de aula com pesquisas cujos dados são apresentados pelos próprios alunos parece satisfazer o professor e leválo a pensar que estaria fazendo um trabalho diferenciado. A professora Tânia declara estar trabalhando com seus alunos da forma como aprendeu e estar descobrindo agora a Estatística como matemática das possibilidades. "Estar descobrindo agora a Estatística" parece referir-se ao momento atual, de participação no grupo.

Franklin et al. (2007, p. 6) destacam que o objetivo principal da Educação Estatística é ajudar os alunos a desenvolver o pensamento estatístico. "O pensamento estatístico, em grande parte, deve lidar com a onipresença da variabilidade; a resolução dos problemas estatísticos e a tomada de decisões dependem da compreensão, interpretação e quantificação da variabilidade nos dados".

Uma dificuldade fundamental no ensino da Estatística é que os alunos estão mais familiarizados com uma visão determinística do mundo, que oferece uma única resposta, baseada na dedução. A Estatística baseia-se na inferência, em vez da dedução. Várias hipóteses podem ser levantadas de um conjunto de dados, cada qual com diferente probabilidade de ser verdadeira. Podemos até pensar em um novo paradigma para o ensino da Matemática, que poderá emergir a partir de um estudo simbólico das estatísticas, ou seja, de um estudo de suas características epistemológicas e do significado de seus termos e noções.

Concordamos com Lopes (2008) sobre a necessidade de estabelecer metas e objetivos para o ensino da Estatística em todos os níveis, em vez de deixar que um apêndice de uns poucos gráficos sejam inseridos no final de alguns capítulos dos livros didáticos com o nome de "Tratamento da Informação". Concordamos também que "os professores precisam realizar investigações para analisarem dados e também experimentos 
probabilísticos a fim de adquirirem conhecimento estatístico e probabilístico de forma interligada com a metodologia e a didática" (LOPES, 2008, p. 73).

Em relação à formação continuada de professores, não acreditamos na eficácia dos programas que lhes são impostos de forma autoritária e, muitas vezes, até desrespeitosa. Ao mesmo tempo, acreditamos que um material de apoio deva estar disponível em órgãos que se destinam a oferecer suporte, caso ele necessite estudar algum tópico do conteúdo ou alguma questão pedagógica do seu interesse. Essa matéria de apoio poderia incluir livros, palestras, cursos, grupos de reflexão. Consideramos relevante que se estabeleçam políticas públicas para que a Educação Estatística desenvolvida nos currículos de nossas escolas possa contribuir para o desenvolvimento da Literacia Estatística dos nossos alunos, ou seja, para a interpretação e a compreensão dos resultados estatísticos, e não apenas para seu cálculo matemático e a representação simplificada de gráficos.

A função da escola está em fase de transformação em razão da globalização e do avanço da tecnologia e das relações internacionais. Nesse sentido, discussões sobre o currículo passam pela análise do sistema educacional do país, de suas necessidades sociais, econômicas e políticas. O cidadão que precisamos formar na escola necessita desenvolver a capacidade de elaborar questões e estratégias para respondê-las, analisando os resultados obtidos. Nesse sentido, é importante "perceber a Estatística como uma Ciência de análise de dados, e não como uma mera aplicação da Matemática" (LOPES, 2008, p. 83).

A Educação Estatística pode vir ao encontro das necessidades de trabalhar com nossos alunos, visando uma formação científica e investigativa. Acreditamos, em primeiro lugar, que uma postura de valorização do aluno e de respeito e incentivo por suas ideias possam fazer diferença para a formação do espírito crítico.

No episódio seguinte, a professora Rita lê uma parte da sua narrativa sobre a aula de Estatística que ministrou para seus alunos. Ele nos ajudou a compreender como o contexto profissional estava dificultando o trabalho do professor.

RITA - Continuando, "estamos diante, pelo menos no discurso, de um momento educacional onde se abre espaço para a formação integral do ser humano, uma vez que as escolas devem abranger os valores éticos e sociais e lutar pela diminuição de desigualdades. $O$ problema que ainda resiste...". Eu tinha que fazer uma crítica, eu tinha que falar que falta isto: "é $a$ garantia de condições estruturais, administrativas e burocráticas para que isso se concretize dentro da escola" (15/07/2008).

A professora Rita declara, de maneira enfática, que tinha que fazer uma crítica, falar sobre as condições estruturais, administrativas e burocráticas da escola. Ela parece referir-se às condições adversas de grande parte das escolas públicas do nosso país e do contexto familiar dos nossos alunos.

Fullan e Hargreaves (2000) defendem que o local de trabalho de professores e estudantes é o elemento central para a reforma que pretendemos implementar no ensino e que as escolas não são, atualmente, locais em que o crescimento individual e cooperativo dos professores e estudantes possa florescer

O fato de o professor atuar dentro de um sistema subordinado à regularização pelo Estado impõe limites à sua autonomia, e a obediência a normas e a diretrizes vindas do Ministério ou das secretarias de Educação limita a sua autonomia, o que o distancia de um grupo profissional que se autocontrola e se conduz de forma independente para o desenvolvimento. Nesse sentido, como destaca Oliveira (2004), as reformas podem lhe tirar a autonomia, entendida como a participação e a organização do seu próprio trabalho.

Concordamos com a autora, quando define a autonomia como o ponto fulcral da luta do professor pela profissionalização, ainda mais se levarmos em conta que ele tem a incumbência de preparar o aluno para fazer frente às demandas que se apresentarão na sua vida futura e, por esse motivo, deve ser também ele, professor, um cidadão crítico e autônomo.

Lüdke e Boing (2004, p. 1166) levantam a questão: "Se, e como, a precarização do trabalho docente pode estar repercutindo sobre a construção da identidade de nossos professores". Acreditamos que a precarização do trabalho docente não somente repercute sobre a construção da identidade dos professores, como produz uma cultura de desvalorização do conhecimento, visto que aquele que recebe da sociedade a incumbência de transmitir o conhecimento formal através da escola tem sido marginalizado e tem, até mesmo, sofrido 
um processo de desprofissionalização.

Fiorentini (2010, p. 28) destaca que, para os professores superarem sua principal limitação profissional, que é a sua reduzida autonomia, "precisavam construir coletivamente uma teoria de ensino por meio da reflexão crítica e da investigação sobre seu próprio trabalho e sobre seus conhecimentos". Destaca também que tanto a prática de ensinar quanto a de pesquisar exige que o professor seja reflexivo, mas que a reflexão é uma condição necessária, mas não suficiente para o professor vir a ser pesquisador. A reflexão, por outro lado, lhe permite levantar questões que podem leválo a um processo de pesquisa, caso ele faça esta opção.

No diálogo abaixo, eu queria saber se a professora Tânia acreditava que outros professores da escola também poderiam beneficiar-se de um estudo mais sistemático de textos teóricos. Esta questão foi motivada pela minha tentativa de compreender o mecanismo gerador da necessidade de o professor desenvolver-se profissionalmente.

PESQUISADORA- E você acha que seria viável a gente tentar motivar os professores para ler um pouco mais, trabalhar um pouco mais com teoria?

TÂNIA - Eu acho. Eu acho que é fundamental. Se bem que é assim, talvez ele esteja no estágio que eu estava, da não aceitação.

PESQUISADORA - Mas você conseguiu fazer isso por causa do seu Mestrado. Não foi?

TÂNIA - Não. Então, mas a minha busca pelo Mestrado...

PESQUISADORA - Já foi por causa dessa inquietação...

TÂNIA - É, porque eu via que não estava dando resultado. A Teia do Saber foi inteirinha prática. E eu coloquei tudo que eu aprendi lá, e eu ensino meus alunos, eu passo dobradura... Eu não vou falar que não é bom. Eu aplico o geoplano hoje, só que eu não usufruo disso para produzir um conhecimento, entendeu? Por quê? Porque não está a teoria (17/12/2007).

Neste episódio, podemos perceber como se estabelecem as relações de sentido no grupo. A professora Tânia respondeu afirmativamente à minha pergunta: se ela achava que seria viável tentar motivar os professores para trabalhar um pouco mais com a teoria; mas apresentou uma ressalva: "talvez ele esteja no estágio que eu estava, da não aceitação". Ela revela que a busca pelo Mestrado foi uma forma de resolver a sua inquietação por melhores resultados em suas práticas. Podemos perceber que a minha posição de outro permitiu que ela fosse se aprofundando na sua reflexão, na sua busca de sentido. Até aquele momento, ela parecia ter dúvida sobre o que surgiu primeiro: a sua inquietação ou o Mestrado. Ela dá também a sua opinião sobre a Teia do Saber, destacando a falta da teoria e de oportunidade para a produção de saberes. Esta reflexão da professora pode ajudar-nos a responder nossa questão investigativa. Quando afirma: "eu coloquei tudo que eu aprendi lá, e eu ensino meus alunos", ela parece declarar sua insatisfação com a situação de dependência e passividade que experimentou na experiência com a Teia do Saber. E quando afirma: "Eu aplico o geoplano hoje, só que eu não usufruo disso para produzir um conhecimento, entendeu? Por quê? Porque não está a teoria", ela pode estar declarando a necessidade de compreender melhor o funcionamento dos processos educativos para produzir saberes e não apenas aplicar técnicas. Este episódio pode também ser um exemplo de produção da sua concepção de teoria, instigada pelas relações dialógicas do grupo. O uso do geoplano como material didático poderia não ter sido problematizado e resignificado sem a oportunidade das interações discursivas.

No episódio a seguir a professora Vânia declara estar olhando a sua sala de aula de maneira diferente depois que começou a estudar e a refletir sobre suas práticas:

PESQUISADORA - Então, antes de você chegar, a Tânia estava falando que agora que ela está estudando, ela está vendo a sala de aula de uma forma diferente.

VÂNIA - Com certeza, eu já estou começando a reparar, lembra que você falava: "Você perguntou isto? Viu aquilo?". Agora eu estou observando algumas coisas, eu pergunto para eles "o que você pensou?", "o quê que você quis dizer com isso?", estou tentando ter essa visão de pesquisadora, sei lá (22/02/2007).

A professora Vânia afirma que está vendo a sala de aula de forma diferente, com uma visão de pesquisadora; deixa claro que hoje percebe sua prática de maneira diferente e parece estar 
desenvolvendo uma postura investigativa com seus alunos. Cochran-Smith e Lytle (1999, p. 294) destacam que "em comunidades nas quais a investigação é uma postura, grupos de professores se envolvem na co-construção do conhecimento através de conversas e outras formas de análise e interpretação colaborativas".

A professora Tânia também relatou, a seguir, uma experiência que teve com seus alunos:

TÂNIA - Eu ia trazer uma cópia de um texto, mas esqueci. É que eles estão tão acostumados a ter "um certo" que eles ficam esperando qual a resposta que o professor deseja que eles escrevam. $O$ aluno não sabe como responder por que aquilo que ele pensou certamente não está certo, $e$ não se acha no direito de expor porque ele sempre estará errado. Eu acho que é isso mesmo, até pouco tempo, eu não enxergava as coisas da forma como enxergo $e$ certamente meus alunos iriam esperar para saber qual resposta eu queria (22/02/2007).

O texto ao qual a professora se refere é um registro escrito dos alunos. Ela destaca a dificuldade que eles têm para expor seus pontos de vista porque "aquilo que ele pensou certamente não está certo". Podemos concluir que estamos negando a nossos alunos o direito de analisar os fatos com espírito crítico e expor suas ideias com liberdade. E estamos deixando de lado os trabalhos com a escrita nas aulas de Matemática.

No diálogo a seguir, a professora Tânia relata a continuidade de uma reflexão que havia iniciado:

TÂNIA - Então, eu comecei a pensar: primeiro você quer resultados rápidos. Então eles fizeram esse projeto para trabalhar com uma classe formada exclusivamente com os multirrepetentes e já estão analisando no final de um ano, enquanto que toda transformação, toda mudança é lenta.

PESQUISADORA - E você já está pensando em aproveitar as diferenças e não em anular.

ANA - Você não acha também que não é apenas o grupo e sim a prática usada para chegar ao grupo?

TÂNIA - Ana, isso está na nossa cultura, na nossa cabeça. Eu falo assim: “eu vou”...
Mentira, porque na hora que eu vou trabalhar lá, eu sei que eu estou separando, entendeu? A ação é uma coisa, e discutir é outra coisa. Então vai demorar, é lento, a minha transformação também vai ser lenta, não vai ser assim... (08/11/2007).

Ela declara ao grupo a forma como conseguiu analisar criticamente $\mathrm{o}$ projeto desenvolvido na escola e conseguiu contemplar o acontecimento de fora, sem fundir-se com ele. Como nos alerta Bakhtin (2006), para que se realize o processo de criação estética, que na nossa problemática é a produção de saberes a partir da prática pedagógica do professor, é necessário que o autor tire proveito dessa posição exotópica.

Tânia demonstra sua alegria, ao perceber que havia avançado um pouquinho. Declara a sua mudança de concepção em relação à constituição dos grupos de estudo. Ela parece estar percebendo que o que havia estudado poderia mudar a sua maneira de ver a realidade e oferecer opções para que ela fosse transformada. Podemos relacionar esse fato com a produção do "conhecimento local" caracterizado por Cochran-Smith e Lytle (1999); as questões que emergiram nessa ação de imbricamento teórico-prático funcionaram como lentes para ver e dar significado à prática. A professora declara que as mudanças nas práticas pedagógicas desafiam as intenções dos professores e que, entre o discurso e a ação, existem fatores que interferem $\mathrm{e}$ impedem que essas mudanças aconteçam de maneira fácil, principalmente os fatores relativos à organização da escola e aos condicionamentos impostos pela família; alguns deles, portanto, de origem cultural.

Em outra reunião, estávamos analisando o texto escrito da aula da professora Rita. A produção de sentido pelo grupo pode ser notada na entonação, ou melhor, nos pensamentos incompletos.

RITA - "Depois de algumas leituras e acompanhamento das aulas de alguns colegas, decidi elaborar a minha aula. Nesse momento o que estava claro para mim é que o tema deveria ser de interesse dos alunos, pois assim participariam mais ativamente dessa experiência".

HELENA - "Pois assim desenvolveriam capacidades requeridas de um cidadão" não fica melhor?

RITA - Mas, olha, minha questão será que só o fato deles terem interesse já vai 
desenvolver...

DIVA - Você poderia dizer...

PESQUISADORA - Quando você escreveu

isto, você quis dizer que o interesse

promove...

RITA - Mas, lendo novamente, achei que tem uma ligação direta e está forte.

PESQUISADORA - Eu acho que o

interesse promove a participação.

RITA - Inclusive, na conclusão, eu cheguei que realmente com um tema de interesse eles participam $(15 / 07 / 2008)$.

O discurso produzido neste diálogo, com muitas reticências, mostra a produção do conhecimento na interação e a busca de um sentido que pudesse satisfazer a todas. As professoras buscavam compreender se realmente o interesse dos alunos era condição necessária e suficiente para a participação deles nas práticas da sala de aula. Felizmente não conseguimos fechar a questão, quando afirmei: "Eu acho que o interesse promove a participação". Assim, ela poderia continuar instigando as reflexões.

De acordo com Bakhtin (2000, p. 353), "em cada palavra há vozes que podem ser infinitamente longínquas, anônimas, quase despersonalizadas". As possibilidades e as perspectivas que estão latentes na palavra são infinitas, de modo que o enunciado sempre cria algo que, antes dele, não existia. Nos nossos diálogos, pudemos perceber que as palavras provocam ideias, nem sempre sobre aquelas às quais elas fazem referência.

Cochran-Smith e Lytle (2009) desenvolveram o conceito de "pesquisa da prática" (esta foi a forma que encontramos para traduzir a ideia das autoras, quando se referem à pesquisa desenvolvida pelos profissionais da Educação, como professores, diretores, coordenadores, etc., em escolas e comunidades de base, em contextos colaborativos). A pesquisa da prática tem como base o reconhecimento do professor como produtor de conhecimento e agente das pesquisas que vêm sendo produzidas no contexto educacional. Esse movimento contrapõe-se ao conceito do professor como técnico, consumidor, recebedor e transmissor do conhecimento produzido por outros, fora da escola, e estimula a reflexão crítica aos sistemas de poder, privilégio e diferenças sociais que predominam nos meios educacionais. As autoras referem-se a esses esforços desenvolvidos coletivamente com o construto "trabalhando a dialética", relativo ao trabalho com as tensões e as contradições entre ideias que têm a ver com pesquisa, prática e conhecimento. Quatro dessas tensões foram destacadas como pilares, que remetem às dicotomias pesquisa-prática, papel do professor-papel do pesquisador, pesquisa conceitual-pesquisa empírica e conhecimento localconhecimento formal.

O primeiro e talvez mais importante deles, de acordo com as autoras, é a assumida dicotomia entre pesquisa e prática, no contexto das universidades, e o status epistemológico do conhecimento gerado pelos práticos, o que levanta a necessidade de repensar o que realmente conta como pesquisa, reinventando cursos e programas, em que a investigação faça parte do currículo e a produção colaborativa do conhecimento seja objetivo a ser perseguido.

O segundo aspecto destacado por CochranSmith e Lytle (2009) é a dicotomia entre o papel do pesquisador e o papel dos práticos, enfraquecendo as fronteiras entre pesquisa e ensino. Quando pesquisa e prática são assumidas como dicotômicas, a análise, a investigação, a teorização são entendidas como parte e parcela do mundo da pesquisa, enquanto a ação, a experiência e o fazer são considerados como pertencentes ao mundo da prática. Em vez de serem olhados como construtos opostos, a investigação e a prática são assumidas como relacionadas uma à outra em tensões produtivas, pelos profissionais da universidade e da escola básica.

O terceiro pilar relaciona-se à dicotomia pesquisa conceitual e pesquisa empírica, que são frequentemente consideradas distintas em Educação, a primeira referindo-se à teoria e à lógica e a segunda com base em dados e evidências. A pesquisa da prática não se encaixa em nenhuma dessas duas categorias: não é apenas empírica nem somente conceitual, mas é "melhor entendida como um híbrido baseado na dialética dos dois", nos dilemas diários e nas contradições da prática (COCHRAN-SMITH; LYTLE, 2009, p. 95). Esse híbrido epistemológico poderia ser representado por pesquisa empírico-conceitual.

Finalmente, a pesquisa da prática bate contra a distinção entre conhecimento local, que é frequentemente desvalorizado devido ao seu uso limitado, e o conhecimento formal, que é mais generalizável e, portanto, possível de ser usado em contextos mais amplos e aplicado publicamente. O conhecimento gerado nas pesquisas da prática é denominado pelas autoras "conhecimento local da 
prática", que influencia a ação local, mas contém estruturas interpretativas e teorias da prática que são úteis e usáveis em outros contextos. É uma perspectiva que rejeita o dualismo conhecimento formal-conhecimento prático e adota a concepção de conhecimento local em contextos globais. "Apesar de toda prática ser local na sua essência, argumentamos que o conhecimento local é interativo com maiores e globais influências e é frequentemente útil publicamente além do contexto local" (COCHRAN-SMITH;LYTLE, 2009, p. 127). Nesse sentido, eventos locais têm tendências e efeitos globalizadores.

$\mathrm{Na}$ perspectiva da investigação como postura, a prática pode ser considerada como o primeiro estágio da pesquisa. $\mathrm{O}$ engajamento em uma sistemática e intencional investigação da prática significa trabalhar colaborativamente para mudar a sala de aula, a escola e outras estruturas institucionais, construindo e reconstruindo estruturas para o conhecimento e o currículo. Nesse sentido, o objetivo não é produzir descobertas, não é simplesmente analisar resultados de testes para identificar áreas a serem pesquisadas, mas criar acesso a todos os estudantes para estimulantes oportunidades de aprendizagem.

ANA - Eles [os alunos] desconhecem, não têm interesse, porque já partem de uma sociedade que não valoriza isso [o conhecimento].

PESQUISADORA - Então, políticas mais amplas de valorização do conhecimento, eu acho que é o que está faltando. É um outro lado para atacar a questão, ao invés de ficar jogando tudo nas costas do professor. ANA - Eu já propus até a escola para pais. TÂNIA - Você acha que é uma coisa necessária?

ANA - Eu acho, porque hoje em dia, o pai acha que é só pôr no mundo. Porque a escola dá café da manhã, a escola dá tudo. Então, põe no mundo e a professora educa (07/12/2007).

As professoras, neste episódio, buscavam uma compreensão para o que estava acontecendo no ensino e, de acordo com Bakhtin (2000), em sua busca de uma compreensão responsiva, a palavra sempre vai mais longe. E os enunciados de umas parecem instigar e completar os enunciados das outras.

De acordo com Cochran-Smith e Lytle
(1999, p. 295), “da perspectiva da investigação como postura, há um quê de ativista na liderança do professor". As autoras destacam que as comunidades de investigação existem para fazer mudanças na vida dos professores e dos alunos e na atmosfera social e intelectual da escola. Neste episódio, é possível perceber esse ativismo, que está vindo substituir a postura acomodada e de reclamação que já foi notada em outras ocasiões. É visível um movimento do grupo, no sentido de um desenvolvimento profissional, de uma preocupação com a Educação que extrapola a sala de aula.

\section{Conclusões}

Podemos indicar o estudo e uma postura investigativa em relação às práticas docentes e ao contexto no qual estas se inserem como pontos de partida para a reprofissionalização docente, ao lado da luta para melhores condições de trabalho. As professoras observaram que os textos elaborados por outros pesquisadores e problematizados no grupo geravam mudanças nas práticas pedagógicas que, por sua vez, eram também problematizadas e analisadas coletivamente. Em nossos estudos, pudemos compreender como a problematização é responsável pela produção de sentido. Pudemos perceber que as palavras provocam ideias, nem sempre diretamente relacionadas àquelas às quais fazem referência e que as ideias contraditórias podem aprofundar a reflexão e instigar a produção de novos sentidos sobre o tema.

A escrita das histórias de aula representou um aprofundamento nas reflexões e permitiu que as ideias ficassem mais claras para todos, mesmo depois que havíamos visto os filmes e analisado oralmente as aulas. A escrita acrescentou um rigor $\mathrm{e}$ uma sistematização que não havíamos encontrado antes. A publicação do livro produzido pelas professoras e as apresentações dos trabalhos em congressos foram decisivos para a sistematização dos saberes produzidos.

A perspectiva de "investigação como postura" (COCHRAN-SMITH e LYTLE, 1999, 2009), na qual a sala de aula é vista com olhar investigativo mudou toda a relação das professoras com a sua prática pedagógica, visto que a geração do conhecimento e sua aplicação são problemáticas, não havendo diferença entre teoria e prática. A postura de investigação coletiva, não apenas individual, se mostrou também de grande importância na sistematização dos saberes das 
professoras e nos processos de aprender e ensinar Estatística. Quando as professoras passaram a adotar, em relação ao conhecimento, uma postura investigativa que envolvia questionamento, seus alunos passaram também a fazer mais perguntas e a estabelecerem mais relações entre os fatos discutidos em sala de aula.

A dimensão social e política do trabalho docente, ou seja, o trabalho em um contexto mais amplo que o da sala de aula, apresentou desafios e possibilidades de superação dos sentimentos de desânimo e falta de motivação das professoras. Percebemos a necessidade de que os outros agentes educativos das escolas trabalhem junto com os professores na organização das atividades e do projeto pedagógico e também a importância de que a comunidade na qual está inserida a escola seja mobilizada, e os pais, integrados em projetos culturais.

Percebemos a necessidade de que se estabeleça uma parceria entre formadores da universidade, professores da escola e futuros professores, visto que o trabalho colaborativo considera a contribuição de diferentes vozes no processo de interação. Por outro lado, a formação e manutenção de grupos do tipo colaborativo demandam recursos públicos e certa autonomia das escolas, para que possam funcionar como alternativa à formação contínua dos professores.

Sob o ponto de vista da Educação Estatística, nosso grupo constatou a existência de sérias limitações de nossa parte para desenvolver um trabalho efetivo com os alunos. A existência de uma perspectiva diferente daquela usada na Matemática, com ênfase no levantamento de hipóteses e na possibilidade de resultados com graus diferentes de probabilidade de ocorrência, é um trabalho para o qual não fomos preparadas e que durante o nosso trabalho de pesquisa apenas conseguimos iniciar.

Pudemos perceber também como o contexto profissional dos professores se impõe, interferindo em suas práticas pedagógicas. Achamos necessário que os professores sejam ouvidos e que seus saberes sejam levados em conta, pois eles podem produzilos a partir de suas práticas pedagógicas. Concluímos que o fato do socializarem seus saberes levou as professoras a um sentimento de poder e de identificação profissional. Percebemos até mesmo um sentimento de entusiasmo em relação à profissão docente.
Nota

1 Os nomes dos professores são fictícios

\section{Referências}

BAKHTIN, M. M. Estética da criação verbal. São Paulo: Martins Fontes, 2000.

BAKHTIN, M. M. Estética da criação verbal. São Paulo: Martins Fontes, 2006.

COCHRAN-SMITH, M.; LYTLE, S. L. Relationships of knowledge and practice: Teacher learning in communities. Review of Research in Education. Washington, DC, USA: American Educational Research Association, n. 24, p. 249305, 1999.

COCHRAN-SMITH, M.; LYTLE, S. L. Inquiry as stance: practitioner research for the next generation. New York, USA: Teacher College Press, 2009.

FIORENTINI, D. Relações entre a formação docente e a pesquisa sobre os processos de conhecimento e a prática dos professores. In: HAGEMEYER, R. C. C. (Org.). Formação docente e contemporaneidade: referências $e$ interfaces da pesquisa na relação universidadeescola. Curitiba: Editora da UFPR, 2010, p. 23-51.

FRANKLIN, C. et al. Guidelines for Assessment and Instruction in Statistics Education (GAISE) Report: a pré-k-12 curriculum framework. Alexandria/VA: ASA, 2007.

FULLAN, M.; HARGREAVES, A. A escola como organização aprendente - buscando uma educação de qualidade. Porto Alegre: Artes Médicas Sul, 2000 .

LOPES, C. A. E. Literacia estatística e o INAF 2002. In: FONSECA, M. C. F. R. Letramento no Brasil: habilidades matemáticas: reflexões a partir do INAF 2002. São Paulo: Global, 2004.

LOPES, C. A. E. Reflexões teórico-metodológicas para a Educação Estatística. In: LOPES, C. E.; CURY, E. Pesquisas em Educação Matemática: um encontro entre a teoria e a prática. São Carlos: Pedro e João Editores, 2008. p. 67-86. 
LUDKE, M.; BOING, L. A. Caminhos da profissão e da profissionalidade docentes. Educação e Sociedade, Campinas, v. 25 , n. 89 , p. 1145-1157, set./dez. 2004.

OLIVEIRA, D. A. A reestruturação do trabalho docente: precarização e flexibilização. Educação e Sociedade, Campinas, v. 25, n. 89, p. 1227-1249, set./dez. 2004.
TARDIF, M. Saberes docentes e formação profissional. Petrópolis, RJ: Vozes, 2002.

ZEICHNER, K; DINIZ-PEREIRA, J. E. Pesquisa dos educadores e formação docente voltada para a transformação social. Cadernos de Pesquisa, São Paulo, v. 35, n. 125, maio/ ago. 2005.

\section{Sobre a autora:}

Maria Aparecida Vilela Mendonça Pinto Coelho: Mestre e Doutora em Educação Matemática pela Universidade Estadual de Campinas (FE/UNICAMP), Campinas, SP - Brasil - Pesquisadora da área de Educação Matemática e de Formação de professores. Professora e pesquisadora do Centro Universitário Claretiano de Batatais no programa de formação de professores e Educação a Distância. 